\title{
THE
}

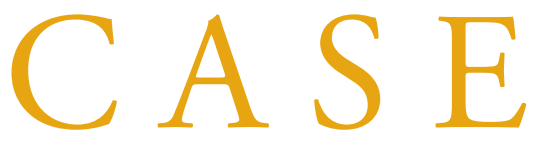

FOR

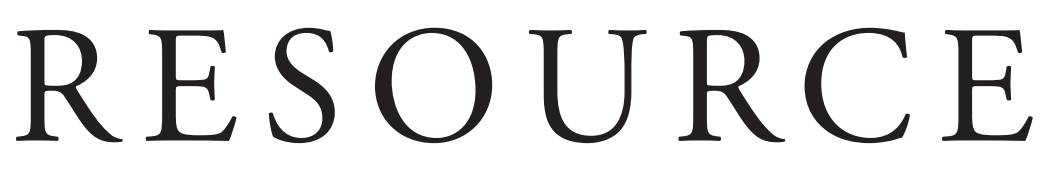

SENSITIVITY

\section{WHY IT IS ETHICAL TO PROVIDE CHEAPER, LESS EFFECTIVE TREATMENTS IN GLOBAL HEALTH}

\author{
BY GOVIND C. PERSAD AND EZEKIEL J. EMANUEL
}

Providing cheaper, less effective treatments is not an unethical double standard, but an appropriate response to different economic contexts. Three fundamental values support the provision of cheaper treatments, even when these treatments are less effective: utility, equality, and priority to the worst off.

W

hen Dr. Hortense screens her patients in Chicago for cervical dysplasia and cancer, she conducts a pelvic exam, takes a sample of cervical cells, and sends them for Pap cytology and human papilloma virus DNA co-testing. ${ }^{1}$ But when she conducts cervical cancer screening in Botswana, she employs a much simpler diagnostic strategy. ${ }^{2}$ She applies acetic acid to highlight precancerous lesions and visually inspects the cervix-a technique known as the VIA (visual inspection with acetic acid) method. She treats suspicious lesions with cryotherapy.

There are multiple reasons that Dr. Hortense uses VIA in developing countries. It requires no

Govind C. Persad and Ezekiel J. Emanuel, "The Case for Resource Sensitivity: Why It Is Ethical to Provide Cheaper, Less Effective Treatments in Global Health," Hastings Center Report 47, no. 5 (2017): 17-24. DOI: 10.1002/hast.764 specialized laboratory facilities or highly trained personnel. With immediate results, there is no delay in diagnosis and treatment, ensuring that patients are not lost to follow-up. Most importantly, VIA is considerably cheaper than Pap and HPV co-testing. ${ }^{3}$

This difference in care between Chicago and Botswana presents an ethical dilemma in global health: is it ethically acceptable to provide some patients cheaper treatments that are less effective or more toxic than the treatments other patients receive? ${ }^{4} \mathrm{We}$ argue that it is ethical to consider local resource constraints when deciding what interventions to provide. The provision of cheaper, less effective health care is frequently the most effective way of promoting health and realizing the ethical values of utility, equality, and priority to the worst off. 
Other Examples of Cheaper, Less Effective Alternatives

T he World Health Organization has not adopted a uniform policy regarding the permissibility of providing cheaper but less effective or more toxic interventions. In some cases, the WHO has recommended cheaper but less effective or more toxic therapies for poor countries. For instance, the WHO argued that VIA "is an attractive alternative to cytology-based screening in low-resource settings." 5 But sometimes the WHO takes the opposite position. For HIV/AIDS, for example, it rejects the provision of cheaper, less effective treatments. Its 2015 treatment standards indicate that "ART [antiretroviral treatment] should be initiated in all adults living with HIV regardless of WHO clinical stage."' Thus, all thirtyseven million HIV-positive patients worldwide should receive ART. The WHO also states that tenofovir-based ART is the preferred first-line HIV treatment. ${ }^{7}$ The WHO has recommended discontinuing the use of cheaper stavudine-based ART "because of its well-recognized metabolic toxicities."

Unfortunately, the provision of alternatives to stavudine faces a major funding gap. Since 2010, global health assistance has remained relatively flat in nominal dollars, ${ }^{9}$ and it appears that funding will not significantly increase in the foreseeable future. ${ }^{10}$ Consequently, only fifteen million-41 percent-of all HIV-positive patients worldwide are receiving ART. Tragically, as the U.S. government puts it, "most people living with HIV or at risk for HIV [still] do not have access to prevention, care, and treatment."11

For medical devices, too, the WHO rejects the provision of cheaper, less effective treatments, arguing, "[T]here should be no double standard in quality. If a [medical device] is unacceptable in the donor country it is also unacceptable as a donation." ${ }^{2}$ This position would bar the reuse of pacemakers, for instance. Pacemakers could help many arrhythmia patients in developing countries. ${ }^{13}$ However, new pacemakers' high cost makes them largely inaccessible. ${ }^{14}$
Nongovernmental organizations seeking to help patients in developing countries have implemented programs to remove, sterilize, and repackage pacemakers from cadavers in developed countries. ${ }^{15}$ Reused pacemakers perform effectively, although not quite as well as new ones. ${ }^{16}$ Currently, the United States and the European Union prohibit domestic reuse of pacemakers, although reuse of devices has sometimes occurred in developed countries. Before Sweden joined the European Union, about 15 percent of implanted medical devices there were reused. ${ }^{17}$ In developing countries, NGOs follow the WHO directive. ${ }^{18}$

In contrast, the WHO has argued that phenobarbital is the preferred treatment for epilepsy in developing countries, even though it is more toxic than some other medications, on the basis that " 61 to $72.8 \%$ of the population in the poorest countries of the African region live on less than US $\$ 1.00$ per day." ${ }^{19}$ Roughly 80 percent of the fifty million people worldwide afflicted with epilepsy live in developing countries. In developed countries, the condition is usually treated with lamotrigine, oxcarbazepine, or other medications that are considered less toxic than the old firstline treatment, phenobarbital. However, phenobarbital remains a first-line treatment in developing countries because of its low cost. ${ }^{20}$ Some have criticized the continued use of phenobarbital as putting "a geographic hierarchy on brain function." 21

Finally, consider the case of meningitis. For bacterial meningitis, a combination of penicillin and chloramphenicol is effective and inexpensive but has serious side effects, particularly aplastic anemia. ${ }^{22}$ In 1997, the WHO recommended providing penicillin and chloramphenicol in developing countries but ceftriaxone, which is effective and safer, in developed countries. ${ }^{23}$ Only in 2005, once ceftriaxone became a low-cost generic, did the WHO recommend it as first-line treatment in developing countries. ${ }^{24}$ In South Africa, however, physicians treating patients with cryptococcal meningitis still face a choice between the more expensive, more effective combination of flucytosine and amphotericin B or the cheaper, less effective option of amphotericin B alone. ${ }^{25}$

\section{Resource Sensitivity, Resource Insensitivity, and Double Standards}

Tn a world without resource constraints, everyone could receive the highest-quality and least-toxic treatments available. But in the real world, outside the happy situation where better treatments are also cheaper, we face the challenge of deciding between quality (providing more expensive treatments to fewer patients) and access (providing cheaper treatments to more patients). Furthermore, some parts of the world face more resource constraints than others.

The resource-sensitive view about these decisions is that interventions should be chosen in light of the opportunity costs of providing them, which vary dramatically depending on what is already being provided in the health care system. As Gro Harlem Brundtland, former WHO director, said, "[I]f services are to be provided for all then not all services can be provided. The most cost-effective services should be provided first." 26 This is the view we will explicate and defend.

In contrast, the position we reject is effectively captured by the WHO stance on drug and device donation: that quality goals should be insensitive to resource constraints. This resource-insensitive view, which holds that whatever treatments are provided in well-resourced settings should also be the standard of care in low-resource settings, is defended by others as well. In the context of drug donation, Cristina Pinheiro asserts that there is an "ethical issue about the existence of first-hand/first-class drugs and second-hand/lower-class drugs," which suggests a "disturbing division between the rights and worth of different populations." 27 A commentary by Nathan Ford and others similarly criticizes countries donating antiretroviral treatments for "applying a double standard by supporting ART care with restrictions to access that they themselves 
would not accept."28 Most recently, Thomas Nicholson and colleagues have interpreted right-to-health provisions as a "stipulation of goldstandard health care for all" and have argued against a "double standard of care that triaged patients by their location in the global economy." ${ }^{28}$ Perhaps the most eloquent presentation of the view that health care should be provided without regard to resource limitations, though, is Paul Farmer's:

[I]t is difficult, perhaps impossible, to meet the highest standards of health care in every situation. But it is an excellent idea to try to do so. Projects striving for excellence-rather than, say, "cost-efficacy" or "sustainability," which are often at odds with social-justice approaches to medicine and public health - are not merely misguided quests for personal efficacy. Such projects respond to widespread demands for equity in health care. ${ }^{29}$

Farmer's call for equity goes wrong when it aims at equity in health care rather than equity in health. Health care, whether it takes the form of antiretrovirals or pacemakers, is merely an instrument to the goal of improving health. ${ }^{30}$ Especially under severe resource limitations, pursuing excellence in health care may not serve the goal of improving the health of the disadvantaged or narrowing health inequalities, let alone the goal of improving population health.

The resource-insensitive position taken by these authors and operationalized in the WHO guidelines on donation would be unobjectionable in an idealized world without resource constraints. This suggests cause for hesitation in applying them to the real world. Aiming to do in nonideal circumstances what would be right under ideal circumstances is less likely to leave us in the position of the person who "shoots for the moon and lands among the stars" than in that of the pilot who got 98 percent of the way to Hawaii. ${ }^{31}$ There are better ways of recognizing that many existing economic disadvantages are unjust and of working to remedy them than acting as though they did not exist. Indeed, ignoring economic realities and opportunity costs is disrespectful to the disadvantaged. Providing patients who face stark resource limitations cheaper, less effective treatments does not regard those patients as inherently less worthy or deserving of rights. Rather, it recognizes that different circumstances produce different priorities.

Critics of resource-sensitive approaches frequently decry them as employing "double standards." 32 We they stem from background injustice, make different responses ethically appropriate in different countries. For example, infertility treatment can be publicly funded in the United Kingdom, where infertility patients and others in the health care system can already access essential medicines; in contrast, offering publicly funded infertility treatments in Nigeria, where many patients lack access to essential medicines, would impose unacceptable opportunity costs that affected the least advantaged most severely. ${ }^{34}$ Public spending on infertility treatments would be unjust because it

\section{For medical devices, too, the WHO rejects the provision of cheaper, less effective treatments, insisting that "there should be no double}

standard in quality. If a [medical device] is unacceptable in a donor

\section{country it is also unacceptable as a donation."}

propose a distinction between two ways that standards might differ according to available resources. The first is to assume that patients in severely resource-limited settings are inherently and fundamentally different from patients in better-off settings and, therefore, that treatment strategies effectively used in the developed world cannot be applied to the developing world. This assumption-exemplified by those who wrongly believed that adherence to HIV medications was impossible in Africa-is an empirical mistake and is rightly criticized. ${ }^{33}$

But there is a second, defensible basis for different standards: even though patients in developing and developed nations have needs of equal moral importance, and even though treatments may be as physiologically effective in developing nations as they are in developed ones, the opportunity costs of providing a given treatment vary dramatically between nations, as do the other problems that patients face. These cross-national differences, even when would inevitably come at the expense of more important health goals. It is no more an unethical double standard to consider economic context when providing treatments than it is to consider medical context: cheaper treatments, just like riskier treatments, may be appropriate in nonideal circumstances, even if they would be inappropriate under ideal circumstances.

The Lancet Commission on Investing in Health has recently endorsed an approach that is resource sensitive. They propose investment to scale up the WHO's essential clinical package in low- and middle-income countries because of its substantial health benefits and low cost: the WHO estimates that scale-up of the essential clinical package to 80 percent coverage across all low- and middle-income countries by 2025 would avert 37 percent of the global burden of cardiovascular disease and diabetes and 6 percent of the global cancer burden. To achieve such coverage would cost an average of 9.4 billion U.S. dollars per year from 2011 to 
2025, representing an annual median cost per person of less than $\$ 1$ in lowincome countries, less than $\$ 1.50$ in lower-middle-income countries, and about $\$ 2.50$ in upper-middle-income countries. ${ }^{35}$

Carrying out the proposal would be a huge step forward for global health at a trivial economic cost, even as it falls far short of achieving what a resource-insensitive standard would call for, namely, access to the full spectrum of health care services even in developing countries. Spending $\$ 2.50$ or less per person per year scarcely compares to the Organisation for Economic Co-operation and Development's average of \$3,514 per capita on health or even the nearly $\$ 1,000$ per capita spent by the lowestspending OECD member, Turkey.

\section{Resource Sensitivity and} Justice

Wisa e have identified reasons to reject a resource-insensitive approach and argued that resourcesensitive approaches do not constitute unethical double standards. A more systematic and foundational case for resource sensitivity is also possible. Three foundational justicerelated values - utility, equality, and priority to the worst off-favor a resource-sensitive view over a resourceinsensitive one.

The value of utility concerns the maximization of population-wide medical benefit. Achieving this goal requires that resources be directed toward the interventions that produce the most medical benefit for a given level of cost. This could, in principle, be achieved by providing expensive treatments that produce major gains in population utility: advocates for a resource-insensitive approach to tuberculosis treatment, for instance, also make the case that providing more expensive drugs would be efficient from a utility-focused perspective. ${ }^{36}$ However, in many cases, including the provision of cervical cancer screening, HIV/AIDS treatment, and medical devices, a resource-sensitive approach that expands access to cheaper, less effective treatments is preferable from a utility standpoint. Two examples include the use of generic antiretrovirals rather than branded ones and the use of external defibrillators rather than implanted devices. ${ }^{37}$

The value of equality emphasizes the reduction of differences between patients' health outcomes. Although the promotion of equality frequently goes hand in hand with the achievement of utility, the two can diverge. For instance, greatly improving the health of a few patients while allowing the worst off to become even worse off might improve utility but not equality. However, despite the attempt by Farmer and others to conceive of resource insensitivity as furthering equity, resource-insensitive views-even if they decrease outcome inequalities between treated patients in severely resource-limited settings and treated patients in betterresourced settings-leave unresolved a much bigger inequality between untreated and treated patients, which could be better addressed through resource-sensitive approaches. Given that there are insufficient resources to cover all thirty-seven million eligible HIV/AIDS patients with tenofovirbased ART treatment, providing fifteen million patients tenofovir-based care means that twenty-two million others will remain untreated..$^{38}$

Finally, if we put a high value on giving priority to the worst off, then we will lean toward assisting those who are most disadvantaged. Typically, the least advantaged people in severely resource-limited settings lack access not only to costly, advanced medical interventions but also to a basic, essential package of care along the lines discussed by the Lancet Commission. ${ }^{39}$ Providing costly treatments that are available in resource-rich settings could deprive many disadvantaged people of access to basic needs. As one example, a recent article on infertility treatment in Nigeria argues that increased access to publicly funded infertility treatment would likely involve "opportunity costs to the worst off Nigerians" that render it "a morally indefensible policy." ${ }^{40}$ Similarly, an article on access to new and costly antiviral treatments for hepatitis $\mathrm{C}$ observes that "groups that are typically underserved by the health system and that tend to have a greater burden of $\mathrm{HCV}$ [hepatitis $\mathrm{C}$ virus] . . . may reasonably demand that inequities in access to the older treatments should be fixed before the newer drugs are made available to the general population." ${ }^{41}$

How resource sensitive should we be? Our view is that choices about the provision of health care should be made in light of their effects on population health rather than in light of any fundamental entitlement to specific health care interventions. The provision of health care in developing countries should reflect what best balances utility, equality, and priority to the least advantaged in those countries, rather than being constrained by choices about health care provision made in developed countries.

We recognize, however, that there is a wide spectrum of possibilities between the thoroughgoing resource sensitivity we defend and the resource insensitivity advocated by our interlocutors. Utility, equality, and priority to the worst off could also be incorporated into a mixed view alongside resource-insensitive components. Possibilities include an approach that allows for a limited gap in quality between interventions provided in developed and developing countries or an approach that sets some threshold of quality below which health care cannot be allowed to fall for any condition, regardless of distributive effects. Such a threshold approach might, for instance, allow the provision of more expensive antiepileptic drugs to individuals who have fared poorly on phenobarbital, even if the opportunity cost of providing these alternatives is undesirable from the perspective of utility, equality, and priority to the worst off. The challenge for proponents of these mixed views is to explain why health care systems should ever 
sacrifice utility, equality, or priority to the worst off in order to provide specific medical interventions. Health (and human flourishing) are more fundamental goals than the provision of health care.

\section{Objections Considered}

A $\mathrm{t}$ least four important objections to the resource-sensitive view are worth considering.

Can't we do both? We can, according to this line of thought, both expand access and improve quality. On this view, resources are not genuinely limited: obtaining sufficient resources is a matter only of will.

It's true that access and quality can both be improved. However, if resources are limited, choices must sometimes be made. Since 2010, financial support for global health has plateaued. Any claim that we need not choose, for instance, between offering fewer total patients the option of cervical cancer screening with cytology and HPV testing and offering more patients the cheaper VIA method, that we can instead simply offer more patients cervical cancer screening with cytology and HPV testing, would need to explain where the additional money will come from. Until that money is identified — and can plausibly be allocated-increased spending on cervical cancer screening with cytology and HPV testing will come at the expense of access for millions, especially in sub-Saharan Africa, who remain untreated.

Even if more money can be obtained for global health, using that money to provide some patients with cervical cancer cytology and HPV cotesting would be a moral mistake so long as millions with cervical cancer remain untreated. In fact, it would be a mistake merely in light of the prevalence of other diseases, such as tuberculosis or neglected tropical diseases, that are rare or unknown in developed nations. The provision of HPV vaccines might be even better at addressing cervical cancer and promoting health than either cytology or VIA followed by treatment. Ultimately, asking, as Ted Schrecker admonishes us to do, "why some settings are consistently and fatally resource poor and others are not" is, while important, not an alternative to or replacement for the project of "proposing substantive criteria or procedural algorithms for setting priorities in 'resource-poor settings." "42 The task of identifying, criticizing, and ameliorating scarcity cannot displace the work of fairly distributing limited resources, but must proceed alongside it.

Resource insensitivity will lower costs. The claim in this objection is be studied case by case. Among the factors that may be relevant in this empirical analysis include the treatment in question, the appeal of the patients, the power of interest groups, and media attention. In the absence of decisive empirical evidence for a future price trajectory, we cannot ignore prices as they are, even though we should always consider what strategies will be most effective at lowering prices in the future.

One mechanism by which resource-insensitive approaches might lower prices is by altering the negotiating position of disadvantaged

\section{Resor \\ Resource-insensitive views decrease inequalities between treated persons in resource-limited settings and treated persons in \\ better-resourced settigns, but they leave unresolved the much \\ bigger inequity between treated and untreated patients.}

that expanded provision of currently expensive interventions that are the standard of care in wealthier countries will lead to lower prices, which will eventually obviate quality-access trade-offs. ${ }^{43}$ Nicholson and colleagues argue, for example, that if the WHO had included more expensive antituberculosis drugs on the essential drugs list, then "their cost may have come down much more quickly due to improved market conditions." ${ }^{44}$ Nicholson et al. go on to conclude that "the cost profile of any protocol is not a static fact to be used as a justification for discrimination."

Indeed, cost profiles may not be static, and we should not assume that they are. But conversely, we should not assume that including a treatment on an essential medicines list will lower the treatment's price. Microeconomic theory predicts that, in the short term, increasing demand will increase, not decrease, prices. ${ }^{45}$ Of course, the assumptions of microeconomic theory are an imperfect fit with the real-world facts of health care pricing. Ultimately, questions about future treatment prices have to patients. If disadvantaged patients do not have the option of selecting cheaper, less effective treatments, sellers may elect to offer them moreeffective treatments at lower prices. ${ }^{46}$ (Yet sellers may instead elect to offer them no treatments at all.) Again, this question is best answered empirically. This empirical examination should also consider alternative negotiation strategies. Recognizing and challenging excessive and unjust prices need not require adopting resource insensitivity. Reducing the demand for marginally effective pharmaceuticals being sold at high prices could also be effective. ${ }^{47}$

The strategy of negotiating on drug prices by removing some less expensive options is also ethically risky. Consider the case of hepatitis C drugs. Some patients with hepatitis $\mathrm{C}$ would prefer older drugs to no treatment at all. Others might refuse older drugs as a protest, analogous to a hunger strike, against the high price of the newer antivirals. Nevertheless, this does not license a decision to subject patients who are not striking to suffering. ${ }^{48}$ Even though 
companies that price their goods unjustly bear moral responsibility when tragic outcomes result, their responsibility does not eliminate the responsibility borne by those who removed the second-best option, just as the misconduct of an employer does not eliminate the responsibility borne by strikers for the consequences of strike-induced disruption..$^{49}$ Recently, Médecins Sans Frontières adopted the strategy of removing treatment options by turning down millions of donated vaccines on the basis that the donors were engaging in unjust pricing practices. ${ }^{50}$ Any evaluation of this strategy must include the suffering and death of potential beneficiaries whose perspectives on refusing donations were not consulted. While gains from better pricing practices might in the future outweigh these beneficiaries' losses, those gains are speculative-and even if they materialize, they might have been achievable without refusing donations.

Providing cheaper, less effective treatments is inequitable. "Efficacy," Farmer and Nicole Gastineau have asserted, "cannot trump equity in the field of health and human rights." 1 Farmer and Gastineau's view might be used to support the objection that providing cheaper, less effective treatments to some and better treatments to others is inequitable.

This objection goes wrong by elevating an instrumental goal-equity of interventions provided-over the more important goal of achieving equitable outcomes. We should not recognize human rights to specific treatments; rather, we should engage in detailed reasoning concerning the costs and benefits of different options, which may vary according to factors like "time, place, economic circumstances, and different priorities." 52 Ignoring the context and effects of providing a given treatment recalls the effort to require parents to purchase separate seats for infants on airplanes, which could have directly saved some infants from death while flying but indirectly cost the lives of many more by leading parents to drive rather than fly. ${ }^{53}$

Guaranteeing specific treatments on the basis that they are used in the developed world would unjustifiably restrict national flexibility. It may be reasonable for citizens of the developing world to use cheaper HIV/AIDS treatments, for instance, and allocate the saved money to address other serious health threats, such as malaria, that developed countries do not face. As John Arras and Elizabeth Fenton put it, whenever we consider a treatment for a given disease, we should ask, "Are there other, competing treatments," whether for that disease or another, "that might yield a greater 'bang for the buck?"' 54 The answer to that question will frequently depend on economic context.

Resource sensitivity would also apply intranationally. An objector might complain that if we are willing to provide cheaper, less effective treatments to the poor in other, developing countries, we should also be willing to do so domestically.

In this discussion, our focus is international rather than intranational, so we comment on this point only briefly. The health gains from intranational resource sensitivity could potentially be great, as the examples of providing cheaper HIV medication and cheaper alternatives to implantable defibrillators show. We conclude that it is reasonable to accept resource sensitivity in both domestic and international settings. ${ }^{55}$ However, solidarity-based arguments for a resource-insensitive perspective are appreciably stronger intranationally and may be strong enough to justify some sacrifice in efficiency, equality, and priority to the worst off. ${ }^{56}$ Accordingly, it is also reasonable to accept resource sensitivity in global health while accepting partial or complete resource insensitivity domestically.

\section{Precedents}

$\mathrm{D}$ ebates surrounding other global issues illustrate that interna- tional norms have moved toward a resource-sensitive approach. Between 1938 and 1986, the Food and Drug Administration prohibited American companies from exporting medicines not approved in the United States. Efforts to relax these restrictions met with opposition based on equality and on rejecting a double standard. One senator complained that exporting drugs that were not approved in the United States sent the unacceptable message "take this drug, use it, it is not good enough for Americans but it is good enough for you" $(s i c .)^{57}$ However, in a 1986 debate over drug exports, Senator Ted Kennedy argued against adopting a single standard of care worldwide. It would be unacceptably arrogant, he said, for Americans to deny people in another country access to a drug on the basis that the risk-benefit ratio would not justify the approval of a drug for use in this country. ${ }^{58}$

Current American drug-export law largely lets importing countries-rather than American regulators - set standards of safety and efficacy. ${ }^{59}$ Similarly, international environmental law has consistently resisted the pressure to be insensitive to context. For instance, the Rio Declaration of 1992 explicitly states that "[e]nvironmental standards, management objectives and priorities should reflect the environmental and developmental context to which they apply. Standards applied by some countries may be inappropriate and of unwarranted economic and social cost to other countries, in particular developing countries." ${ }^{\prime 60}$ Similar language appears in other human-rights agreements, such as Agenda 21, the Framework Convention on Climate Change, and the Stockholm Declaration. ${ }^{61}$ These international norms all favor permitting developing countries to pursue incremental progress rather than imposing developed countries' standards worldwide.

These are important precedents for the problem of how to provide medical care in developing countries. They provide additional warrant 
for the resource-sensitive view that promoting global health should be sensitive to resource limitations and allow the provision of less effective or more-toxic interventions in resourcelimited settings.

\section{Notes}

1. U.S. Preventive Services Task Force, "CervicalCancer:Screening," released March 2012, accessed December 2015, http:// www.uspreventiveservicestaskforce.org/ Page/Document/UpdateSummaryFinal/ cervical-cancer-screening.

2. World Health Organization, "Prevention of Cervical Cancer through Screening Using Visual Inspection with Acetic Acid (VIA) and Treatment with Cryotherapy," 2012, accessed December 2015, http://www.who.int/reproductivehealth/ publications/cancers/9789241503860/en/.

3. Ibid.

4. The possibility of such treatments is discussed in D. M. Kent, A. M. Fendrick, and K. M. Langa, "New and Dis-Improved: On the Evaluation and Use of Less Effective, Less Expensive Medical Interventions," Medical Decision Making 24, no. 3 (2004): 281-86, and in A. L. Nelson et al., "Much Cheaper, Almost as Good: Decrementally Cost-Effective Medical Innovation," $A n$ nals of Internal Medicine 151, no. 9 (2009): 662-67.

5. World Health Organization, "Prevention of Cervical Cancer through Screening Using Visual Inspection with Acetic Acid (VIA) and Treatment with Cryotherapy."

6. World Health Organization, "Consolidated Guidelines on the Use of Antiretroviral Drugs for Treating and Preventing HIV Infection: What's New," November 2015, accessed December 2015, http:// www.who.int/hiv/pub/arv/15249_ HIVTreatementandCare_PolicybriefforWEB.pdf?ua $=1$.

7. World Health Organization, "Consolidated Guidelines on the Use of Antiretroviral Drugs for Treating and Preventing HIV Infection," June 2013, accessed December 2015, http://www.who.int/hiv/ pub/guidelines/arv2013/en/.

8. World Health Organization, "Consolidated Guidelines on the Use of Antiretroviral Drugs for Treating and Preventing HIV Infection: What's New."

9. University of Washington Institute for Health Metrics and Evaluation, "Financing Global Health 2012: The End of the Golden Age?," accessed August 2015, at http://www.healthmetricsandevaluation.org/sites/default/files/ policy_report/2011:FGH_2012_chapter _3_IHME.pdf; University of Washington Institute for Health Metrics and Evaluation, "Financing Global Health 2013: Transition in an Age of Austerity," accessed August 2015, http://www.healthdata.org/policyreport/financing-global-health-2013-transition-age-austerity.

10. University of Washington Institute for Health Metrics and Evaluation, "Financing Global Health 2013.”

11. AIDS.gov, "Global HIV/AIDS Overview," 2013, accessed August 2015, http://aids.gov/federal-resources/ around-the-world/global-aids-overview/.

12. World Health Organization, Medical Device Regulations: Global Overview and Guiding Principles (Geneva, Switzerland: WHO, 2003), http://www.who.int/medical_devices/publications/en/MD_Regulations.pdf.

13. K. G. Aragam et al., "The Ethics of Pacemaker Reuse: Might the Best Be the Enemy of the Good?," Heart 97 (2011): 2005-6.

14. J. VanArtsdalen et al., "Pacemaker Reuse for Patients in Resource Poor Countries: Is Something Always Better Than Nothing?," Progress in Cardiovascular Diseases 55 (2012): 300-306.

15. Aragam et al., "The Ethics of Pacemaker Reuse."

16. Ibid.

17. C. L. Linde et al., "Re-used Pacemakers-as Safe as New?," European Heart Journal 19 (1998): 154-57.

18. MRSO (Medical Surplus Recovery Organization) Network, Code of Conduct, 2012, accessed August 2017, http:// www.chausa.org/docs/default-source/ international-outreach/medical-surpluscode-of-conduct.pdf; The Royal Australian and New Zealand College of Radiologists, "Position Statement on International Development Activities in Radiology and Radiation Oncology," December 17, 2013, accessed August 2014, https://www.ranzcr. $\mathrm{com} /$ search/international-developmentactivities-position-statement; Strengthening Specialised Clinical Services in the Pacific, "SSCSIP Biomedical Meeting for PICs Generic Donation Policy," accessed August 2014, http://sscsip.org/wp-content/ uploads/2013/07/donation_policy1.pdf.

19. World Health Organization, Epilepsy in the WHO African Region: Bridging the Gap (Brazzaville, Congo: World Health Organization, 2004).

20. S. D. Shorvon and P. J. Farmer, "Epilepsy in Developing Countries: A Review of Epidemiological, Sociocultural, and Treatment Aspects," Epilepsia 29, supplement s1 (1998): S36-S54; World Health Organization, Atlas: Epilepsy Care in the World, 2005 (Geneva, Switzerland: World Health Organization, 2005).

21. E. L. Gouveia et al., "Clinical Outcome of Pneumococcal Meningitis during the Emergence of Penicillin-Resistant Streptococcus Pneumoniae: An Observational
Study," BMC Infectious Diseases 11 (2011): 323.

22. World Health Organization, Antimicrobial and Support Therapy for Bacterial Meningitis in Children, report of the meeting of June 18-20, 1997, Geneva, Switzerland.

23. World Health Organization, "Standardized Treatment of Bacterial Meningitis in Africa in Epidemic and Non Epidemic Situations," 2007, http://www.who.int/csr/ resources/publications/meningitis/WHO_ CDS_EPR_2007_3.pdf.

24. T. Boyles, "Is Stavudine Worth Saving?," Southern African Journal of HIV Medicine 13 (2012): 83.

25. G. H. Brundtland, "Message from the Director-General," in The World Health Report 1999: Making a Difference, World Health Organization (Geneva, Switzerland: WHO, 1999), vii-xix, xv.

26. C. P. Pinheiro, "Drug Donations: What Lies Beneath," Bulletin of the World Health Organization 86, no. 8 (2008): 580A.

27. N. Ford, A. Calmy, and S. Hurst, "When to Start Antiretroviral Therapy in Resource-Limited Settings: A Human Rights Analysis," BMC International Health and Human Rights 10, no. 1 (2010): 6.

28. T. Nicholson et al., "Double Standards in Global Health: Medicine, $\mathrm{Hu}-$ man Rights Law and Multidrug-Resistant TB Treatment Policy," Health and Human Rights 18, no. 1 (2016): 85-102.

29. P. Farmer, "Pathologies of Power: Rethinking Health and Human Rights," American Journal of Public Health 89 (1999): 1486-96, at 1492.

30. Here we agree with J. Arras and E. M. Fenton who point out that there may be "other, perhaps better ways to indirectly advance health through social determinants rather than directly with health care" ("Access to Health-Related Goods," Hastings Center Report 39, no. 5 [2009]: 27-38, at 33). Health, of course, may itself be an instrument to the ultimate goals of justice and human flourishing. But it is much closer to those goals than health care is.

31. J. Heath, Economics without Illusions: Debunking the Myths of Modern Capitalism (New York: Crown Business, 2010), 72.

32. The charge of double standards was also common in debates over the appropriate standard of care in international clinical research. Some defended a single, global standard of care, while others argued that the standard of care could permissibly vary according to local context. For an overview, see D. Orentlicher, "Universality and Its Limits: When Research Ethics Can Reflect Local Circumstances," The Journal of Law, Medicine \& Ethics 30, no. 3 (2002): 40310. However, in clinical care-rather than clinical research-two of the arguments that the standard of care should be the same 
worldwide, focused on exploitation and on special duties of researchers to trial participants, do not apply (see Orentlicher, "Universality and Its Limits," 406-7).

33. See J. Moatti, B. Spire, and M. Kazatchkine, "Drug Resistance and Adherence to HIV/AIDS Antiretroviral Treatment: Against a Double Standard Between the North and the South," AIDS 18 (2004): S55-S61.

34. O. Akinloye and E. Truter, "A Review of Management of Infertility in Nigeria: Framing the Ethics of a National Health Policy," International Journal of Women's Health 3 (2011): 265. Orentlicher similarly concludes that "[w]e can employ a universal set of standards whose application may vary depending on local resources" ("Universality and Its Limits," 405).

35. D. T. Jamison et al., Global Health 2035: A World Converging within a Generation," The Lancet 382 (2013): 1899-1955.

36. T. Nicholson et al., "Double Standards in Global Health: Medicine, Human Rights Law and Multidrug-Resistant TB Treatment Policy," Health and Human Rights 18, no. 1 (2016): 85-102.

37. R. P. Walensky et al., "Economic Savings versus Health Losses: The Cost-Effectiveness of Generic Antiretroviral Therapy in the United States," Annals of Internal Medicine 158, no. 2 (2013): 84-92; P. Cram et al, "Implantable or External Defibrillators for Individuals at Increased Risk of Cardiac Arrest: Where Cost-Effectiveness Hits Fiscal Reality," Value in Health 9, no. 5 (2006): 292-302.

38. Boyles, "Is Stavudine Worth Saving?"

39. Akinloye and Truter describe the worst off as undernourished children under five years of age, as well as others who are severely undernourished ("A Review of Management of Infertility in Nigeria," 265). In "Prioritarianism for Global Health Investments: Identifying the Worst Off," Daniel Sharp and Joseph Millum similarly identify the worst off in global health as children whose health is in jeopardy, frequently from cheaply treatable illnesses (Journal of Applied Philosophy [2015]: epub ahead of print, doi: 10.1111/japp.12142).

40. Akinloye and Truter, "A Review of Management of Infertility in Nigeria," 265.

41. J. Urrutia, T. Porteny, and N. Daniels, "What Does It Mean to Put New
Hepatitis C Drugs on a List of Essential Medicines?," BMJ 353 (2016): i2035.

42. See T. Schrecker, "Denaturalizing Scarcity: A Strategy of Enquiry for PublicHealth Ethics," Bulletin of the World Health Organization 86, no. 8 (2008): 600-605, p. 605. Schrecker's scare quotes around "resource-poor settings" are puzzlingthat resource-poor settings are frequently resource-poor due to structural injustices does not make their resource poverty any less real.

43. Nicholson et al., "Double Standards in Global Health," 95.

44. Ibid. The charge of discrimination is uncharitable: the judgments in plausible resource-sensitive approaches are based on real-world opportunity costs, not on invidious stereotypes.

45. See, for example, W. A. McEachern, Economics: A Contemporary Introduction (Boston: Cengage, 2008), 254.

46. For two discussions of how removing certain options might be an effective bargaining strategy, see E. Athanasiou, A. J. London, and K. J. S. Zollman, "Dignity and the Value of Rejecting Profitable but Insulting Offers," Mind 124 (2015): 44243, and A. Wertheimer, "Book Review: Terrance McConnell, Inalienable Rights," Law and Philosophy 20, no. 5 (2001): 541-51, at 544.

47. T. Fojo and C. Grady, "How Much Is Life Worth?: Cetuximab, Non-Small Cell Lung Cancer, and the $\$ 440$ Billion Question," Journal of the National Cancer Institute 101, no. 15 (2009): 1044-48.

48. This is so especially if their suffering is not merely a side effect of the choice not to provide older drugs but also serves as a way of drawing attention to unjust pricing.

49. See I. Grosskopf, G. Buckman, and M. Garty, "Ethical Dilemmas of the Doctors' Strike in Israel," Journal of Medical Ethics 11, no. 2 (1985): 70-71.

50. J. Smith, "When Free Is Not Fair: The Case of Vaccine Donations," The Lancet Infectious Diseases 17, no. 2 (2017): 12830 . While the donated vaccines do not fall into the category of cheaper, less effective treatments, the strategy of refusing them resembles the potential strategy of turning down cheaper, less effective treatments.

51. P. Farmer and N. Gastineau, "Rethinking Health and Human Rights: Time for a Paradigm Shift," The Journal of Law, Medicine \& Ethics 30 (2002): 655-66.

52. Arras and Fenton, "Access to HealthRelated Goods," 36.

53. D. Bishai, "Hearts and Minds and Child Restraints in Airplanes," Archives of Pediatrics \& Adolescent Medicine 157, no. 10 (2003): 953-54.

54. Arras and Fenton, "Access to HealthRelated Goods," 33.

55. For a discussion of domestic resource sensitivity, see B. J. Krohmal and E. J. Emanuel, "Access and Ability to Pay: The Ethics of a Tiered Health Care System," Archives of Internal Medicine 167, no. 5 (2007): 433-37.

56. See Orentlicher, "Universality and Its Limits," p. 406.

57. Statement of Sen. Howard Metzenbaum, Congressional Record 132 (1986): S5655-01.

58. Statement of Sen. Edward Kennedy, Congressional Record 132 (1986): S5655-01.

59. A. H. Kaplan, "Fifty Years of Drug Amendments Revisited: In Easy-to-Swallow Capsule Form," Food \& Drug Law Journal 50 (1995): 179, 193

60. United Nations Conference on Environment and Development, Rio Declaration on Environment and Development, principle 11, U.N.Doc. A/Conf. 151/5 at 4, reprinted in 31 I.L.M. at 878.

61. United Nations, United Nations Conference on Environment and Development, "United Nations Framework Convention on Climate Change," May 9, 1992, in Report of the Intergovernmental Negotiating Committee for a Framework Convention on Climate Change on the Work of the Second Part of Its Fifth Session, INC/FCCC, 5th session, 2d Part, at Annex I, U.N. Doc. A/ AC.237/18 (Part II)/Add.1 (identical text to the Rio Declaration); United Nations, United Nations Conference on Environment and Development, Agenda 21, ch. 2, para. 2.20, Annex II, U.N. Doc. A/ CONF.151/26/Rev.1 (1992); United Nations, United Nations Conference on the Human Environment, Report of the United Nations Conference on the Human Environment, 26th session, princ. 23, U.N.Doc. A/ CONF.48/14 (1972); 11 I.L.M. 1416, 1420. 